\title{
CROHN'S DISEASE OF THE STOMACH
}

\author{
A Report of a Case
}

\author{
By J. B. Self, M.B., B.Chir., F.R.C.S. \\ Formerly Senior Surgical Registrar at the University College Hospital of the West Indies
}

Crohn's disease of the stomach appears to be a rare condition. A search of the literature reveals very few recorded cases.

Ross (1949) was the first to describe a case of Crohn's disease above the small intestine. $\mathrm{He}$ described a patient attending the Lahey Clinic with typical Crohn's disease of the ileum who had numerous resections of small bowel over a period of three years. At the end of this time a lesion appeared in the stomach. It was a localized mass on the greater curvature, $5 \mathrm{~cm}$. in diameter, with an ulcer $\mathrm{I} \mathrm{cm}$. in diameter on the mucosal surface. The stomach wall was inflamed and oedematous. The mass was adherent to the pancreas and extended into the pedicle of the middle colic vessels.

The other recorded cases are all rather different and the case described in this article resembles them more closely.

The next cases were described by Comfort, Weber, Baggenstoss and Kiely (1950). They described five cases, two involving duodenum only and three stomach and duodenum. The two duodenal cases had involvement of the adjacent jejunum. The gastric cases presented with upper abdominal discomfort and nausea with, or without vomiting, and with a bowel upset, diarrhoea or steatorrhoea. The radiological appearances varied. The first case had a dilated hypomotile stomach. Gastroscopy showed diffuse superficial ulceration. Laparotomy showed an oedematous stomach with enlarged oedematous lymph nodes in the omentum. (This is the only case so far described with enlarged omental nodes.) A gastro-enterostomy performed to relieve the retention showed a granular oedematous mucosa in the jejunum although the serosa was normal. Their second case again radiologically showed a hypomotile stomach and duodenum. Laparotomy showed the wall of the stomach and duodenum to be thickened and oedematous. The intestine was normal and the jejunal lymph glands only were enlarged. A post mortem three years later showed the entire stomach mucosa covered with superficial ulcerations with intervening nodular hyperplasia, and again there were no enlarged omental glands. Microscopy of the stomach showed granulomatous inflammation with giant cells, polymorphs and plasma cells. The small bowel was involved and there were numerous large and partly necrotic mesenteric glands. Their third case radiologically only showed duodenal involvement but on laparotomy disclosed an oedematous inflamed pylorus as well. Biopsy of the stomach showed a granulomatous lesion with giant cells. Radiologically all their five cases showed disturbed gastric and or duodenal motility with constriction or dilatation. The constriction was tubular if present.

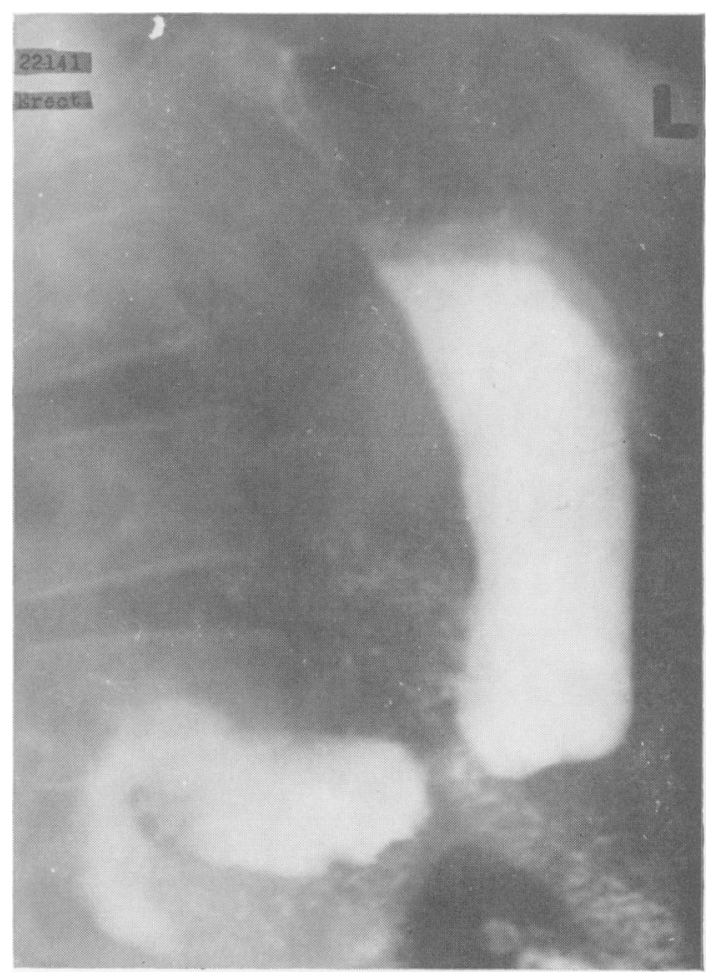

Fig. I.-Barium meal showing the small tubular stomach and abnormal duodenal mucosa. 

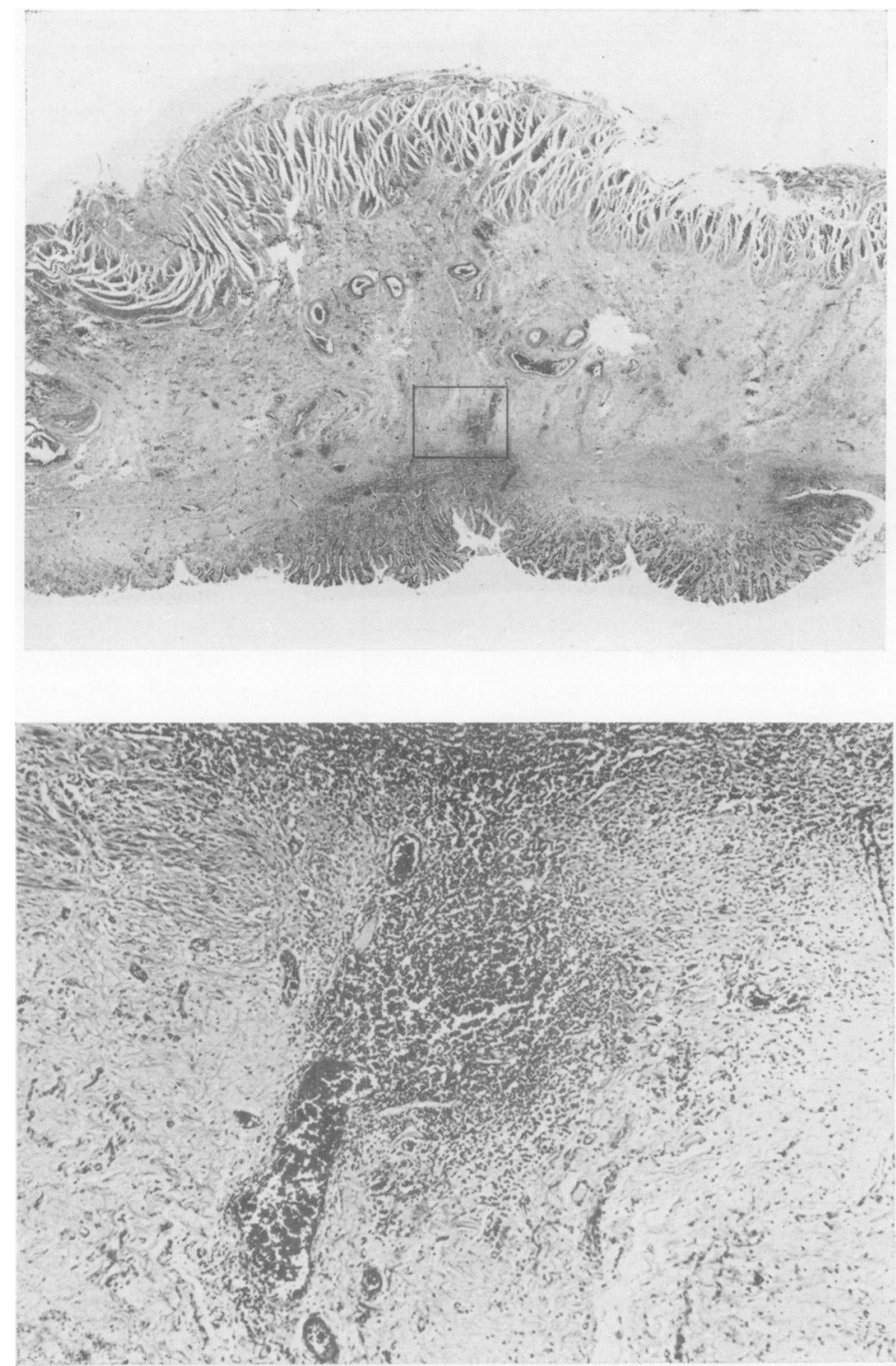

Fig. 2.-A. Low power photomicrograph of the pylorus showing the submucosa thickened by granulation tissue.

B. Further enlargement of area marked in A.

Martin and Carr (1953) described two cases, both presenting with nausea but one with anorexia and the other with epigastric discomfort. Radiologically both had absent peristalsis of the pylorus and the first half of the duodenum, with a deficient mucosal pattern. Both cases had ileal changes, one before the gastric symptoms appeared, the other after the onset of gastric changes. Their first case had a laparotomy which showed typical ileal changes and patches in the colon. The $\widetilde{N}$ stomach wall was a little thickened. A biopsy $N$ revcaled the stroma of the stomach to be heavily N infiltrated with lymphocytes, plasma cells and endothelial cells, giant cells were also present. They note that clinically this case was very similar to a linitis plastica.

The following case has features in common with all the recorded cases of Crohn's disease of the 


\section{A book for the postgraduate}

\section{Practical Obstetric Problems}

by IAN DONALD

M.B.E., M.D. (Lond.), F.R.C.O.G.

Regius Professor of Midwifery, University of Glasgow

"There is no better concise yet reasonable statement of the modern practice of obstetrics."

Brit. Med.J.

". . . this book is likely to become the standby of the obstetric practitioner and especially of the aspirant for higher degrees, for it presents a well-balanced account of modern obstetric practice."

J. Obstet. Gynaec. Brit. Emp.

$x i i+578 p p$

115 illustrations

(1955) 47s. 6d. net

\section{A new \\ monograph}

\section{Anaesthetic Accidents}

by V. KEATING

M.B., B.Ch., D.A., F.F.A. R.C.S.

Consultant Anaesthetist and Lecturer in Anaesthetics,

University College Hospital of the West Indies

This work correlates current opinion on the prevention, diagnosis and treatment of the immediate and remote complications of general and regional anaesthesia, with each section of the book illustrated by the author's personal observations. Anaesthetic accidents are relatively uncommon, but when they do occur they may lead to the death or life-long invalidism of the patient; thus a knowledge of the experience of others and pertinent experimental facts are important.

$v i i+261 p p$.

13 illustrations

(1956) 25s. net

\section{Lloyd-Luke (Medical Books) Ltd., 49, Newman Street, W.I}

stomach which have been reviewed above, and in view of the rarity of the condition it is thought worth while recording.

\section{Case Report}

A coloured woman, aged 35 , presented herself on September 23, 1954, at the University College Hospital of the West Indies complaining of anorexia for one year and vomiting for the previous five months. She had pain in the epigastrium worse on eating and relieved by vomiting. She had diarrhoea with bowel actions about four times daily. She had lost a great deal of weight in the past five months. On examination she appeared wasted and anaemic. Abdominal examination revealed no tenderness and no distension. Rectal examination showed no abnormality. A barium meal was done (Fig. I), and the report was as follows :

Oesophagus : Normal.

Stomach : The gastric capacity was considerably reduced and the patient vomited the barium back after only a few mouthfuls. The muscosal outline was flattened and atrophic; towards the lower end there was a constant incisura and the gastric wall in the pyloric antrum showed some constant filling defects, with very poor peristalsis. The stomach was fairly mobile but definitely less pliable than normal.
Duodenum : The cap was small but appeared to fill normally, the duodenal mucosa was irregular and coarsened.

Conclusion : The appearances suggest a malignant stricture in the lower part of the stomach with widespread infiltration along the gastric wall producing a linitis plastica.

She was admitted to hospital on October ro, I954, with a diagnosis of carcinoma of the stomach. Haemoglobin was 8.5 g. per cent. W.R. and Kahn negative. Blood urea was $16 \mathrm{mg}$. per $100 \mathrm{ml}$. The serum electrolytes were within normal limits. In view of her anaemia and history of persistent vomiting she was given a pint of blood and one litre of Darrow's solution intravenously on October I4, I954.

A laparotomy was performed on October 15, $_{5}$ 1954. The stomach was very small being only 5 inches long, it was narrow and tubular and diffusely thickened from oesophagus to pylorus. No enlarged glands were present in the omentum or mesentery. It was thought that this was a carcinoma and a total gastrectomy was commenced. The greater and lesser omenta were mobilized and the first part of the duodenum mobilized and divided. At this stage the duodenal mucosa was found to be nodular with small ulcers $\mathrm{I}-2 \mathrm{~mm}$. in diameter as far as could be felt by a finger 
inserted into its lumen. No thickening was palpable from the outside. The small bowel was normal from external examination. The stomach was removed and the oesophagus anastomosed to the duodenum. The patient received a further pint of blood postoperatively.

The patient made rapid progress and was discharged eating well on October 30 , 1954. Unfortunately she failed to return to the follow-up clinic and could not be traced at the address she had given so that further barium studies including the jejunum and ileum could not be made.

On opening the stomach diffuse thickening of the wall was found, maximal at the pyloric antrum. A few minute superficial ulcers were present. Numerous sections (Fig. 2) were studied from different parts of the stomach and the changes were the same throughout. The histological report was as follows : "The sections show that the stomach wall is grossly thickened. The mucosa appears everywhere intact and the lamina propria is heavily infiltrated with chronic inflammatory cells and a few polymorphs. The submucosa is thickened by granulation tissue in which the arteries show varying degrees of obilterative arteritis. At varying depths in the submucosa there are small granulomas with numerous macrophages of epithelioid type, multinucleated giant cells and some lymphocytes. There is no evidence of caseation or anistropic material, or acid fast bacilli in the sections.'

\section{Conclusions}

The cases reviewed, together with the case described in this article, all seem to fit into a $\stackrel{0}{0}$ definite pattern. They presented with upper abdominal discomfort and nausea and with a 3 bowel upset. Radiologically there was disturbed $\stackrel{\AA}{\circledR}$ gastric motility and if a constriction was present $c$. it was tubular. There may also be evidence $\vec{\Rightarrow}$ of Crohn's disease in the small bowel, and the $\stackrel{9}{+}$ duodenum is frequently involved at the same time as the stomach, as shown by coarsening of the $\frac{\bar{\sigma}}{\bar{N}}$ mucosal pattern and hypomotility. When seen at $\frac{\sigma}{\nabla}$ laparotomy the stomach wall is thickened and $\cong$ oedematous and in all but one of the cases so far described there have been no omental lymph nodes $\overrightarrow{0}$ enlarged despite mesenteric glandular enlargement if the small bowel is involved. Histology $\vec{\omega}$ shows the same non-specific granulomatous $\frac{2}{8}$ reaction as is seen in the ileum.

\section{Summary}

The recorded cases of Crohn's disease of the stomach are briefly reviewed. An additional case $i$ is described.

I should like to thank Professor G. H. C. Ovens, 은 in one of whose beds this patient was treated, for $c$ permission to publish this case, Dr. W. R. Cole for the $\mathrm{X}$-rays and the Photographic Department, St. Thomas's Hospital, London, for the photomicrographs.

\section{REFERENCES}

COMFORT, M. W., WEBER, H. M., BAGGENSTOSS, A. H and KIELY, W.' F. (1950), Amer.'F. Med. Sci., 220, 616. MARTIN, F. R. R., CARR, R. J. (1953), Brit. med. F., i, 700. ROSS, J. R. (1949), Gastroenterology, $\mathrm{r}_{3}, 344$.

\section{HEPATIC DISEASE}

(Postgraduate Medical Journal, October, 1956)

Price: 3s. 9d. post free

JAUNDICE

Sheila Sherlock, M.D., M.R.C.P

HEPATIC COMA

J. M. Walshe, M.A., M.R.C.P.

SURGICAL TREATMENT OF PORTAL HYPERTENSION

A. I. S. Macpherson, Ch M., F.R.C.S.E.

WILSON'S DISEASE

A. G. Bearn, M.D.
ASCITES IN LIVER DISEASE

Michael Atkinson, M.D. (Lond.)

M.R.C.P.

\section{PSYCHIATRIC ASPECTS OF LIVER} DISEASE

Esther A. Davidson, M.R.C.P.Ed., and

W. H. J. Summerskill, M.A., M.R.C.P.

PERCUTANEOUS PORTAL VENOGRAPHY

David Sutton, M.D., M.R.C.P., .F.F.R.

Published by

THE FELLOWSHIP OF POSTGRADUATE MEDICINE

60, Portland Place, London, W.1 